\title{
Coupled Bison/Thermochimica Simulation of Hydride Formation in Zircalloy Cladding
}

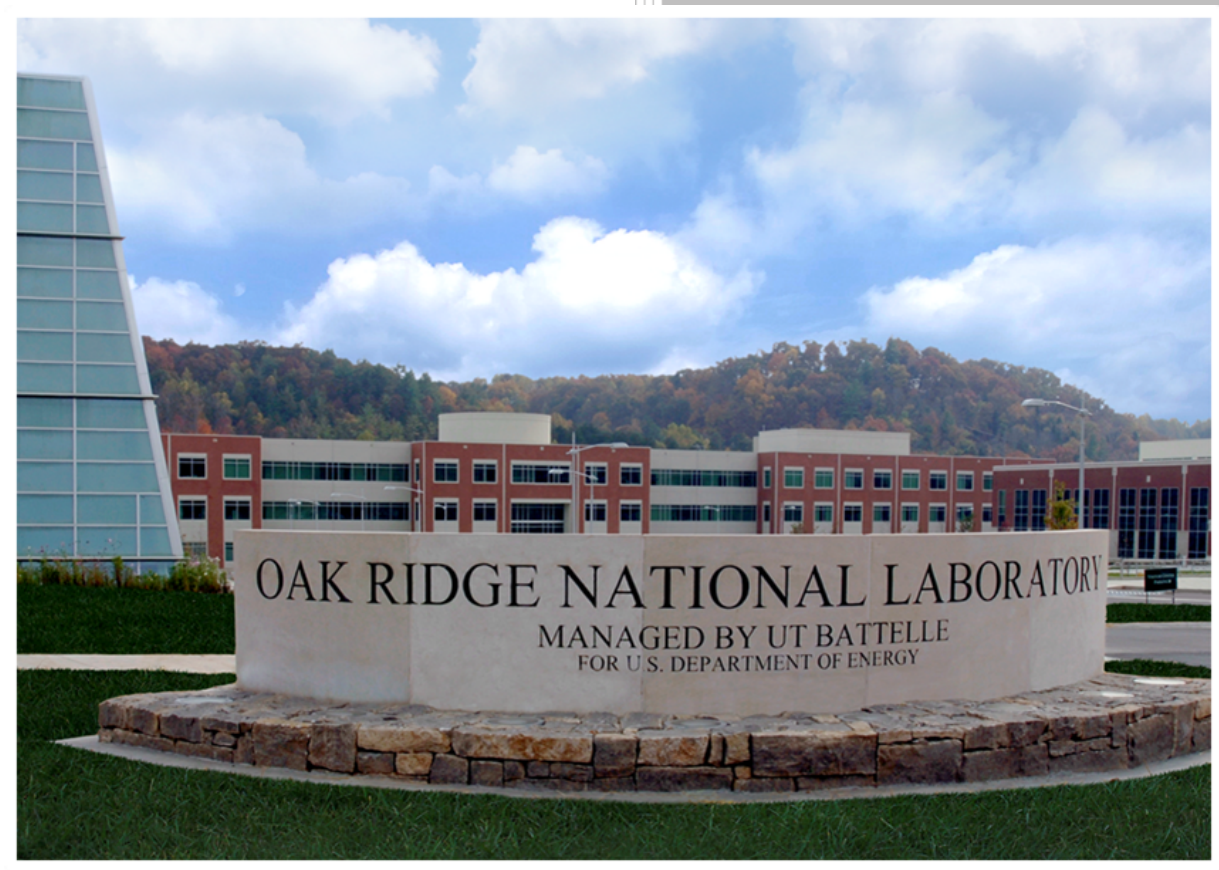

\section{Approved for public release.} Distribution is unlimited.
S. Simunovic
B. Gaston
T. M. Besmann

31 January 2017 


\title{
DOCUMENT AVAILABILITY
}

Reports produced after January 1, 1996, are generally available free via US Department of Energy (DOE) SciTech Connect.

Website http://www.osti.gov/scitech/

Reports produced before January 1, 1996, may be purchased by members of the public from the following source:

\author{
National Technical Information Service \\ 5285 Port Royal Road \\ Springfield, VA 22161 \\ Telephone 703-605-6000 (1-800-553-6847) \\ TDD 703-487-4639 \\ Fax 703-605-6900 \\ E-mail info@ntis.gov \\ Website http://www.ntis.gov/help/ordermethods.aspx
}

Reports are available to DOE employees, DOE contractors, Energy Technology Data Exchange representatives, and International Nuclear Information System representatives from the following source:

Office of Scientific and Technical Information

PO Box 62

Oak Ridge, TN 37831

Telephone 865-576-8401

Fax 865-576-5728

E-mail reports@osti.gov

Website http://www.osti.gov/contact.html

This report was prepared as an account of work sponsored by an agency of the United States Government. Neither the United States Government nor any agency thereof, nor any of their employees, makes any warranty, express or implied, or assumes any legal liability or responsibility for the accuracy, completeness, or usefulness of any information, apparatus, product, or process disclosed, or represents that its use would not infringe privately owned rights. Reference herein to any specific commercial product, process, or service by trade name, trademark, manufacturer, or otherwise, does not necessarily constitute or imply its endorsement, recommendation, or favoring by the United States Government or any agency thereof. The views and opinions of authors expressed herein do not necessarily state or reflect those of the United States Government or any agency thereof. 
Computer Science and Mathematics Division

\title{
COUPLED BISON/THERMOCHIMICA SIMULATION OF HYDRIDE FORMATION IN ZIRCALLOY CLADDING
}

\author{
S. Simunovic ${ }^{1}$ \\ B. Gaston ${ }^{2}$ \\ T. M. Besmann ${ }^{2}$ \\ ${ }^{1}$ Oak Ridge National Laboratory, Oak Ridge, TN \\ ${ }^{2}$ University of South Carolina, Columbia, SC
}

Date Published: January 31, 2017

Prepared by

OAK RIDGE NATIONAL LABORATORY

Oak Ridge, TN 37831-6283

managed by

UT-BATTELLE, LLC

for the

US DEPARTMENT OF ENERGY

under contract DE-AC05-00OR22725 



\section{CONTENTS}

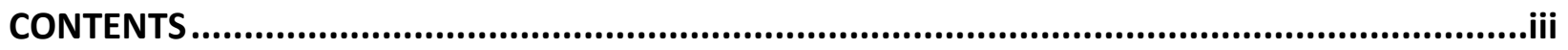

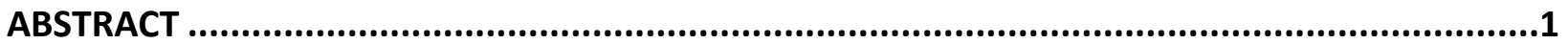

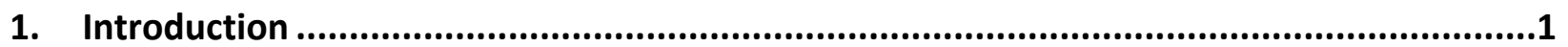

2. Thermodynamic models for zirconium - hydrogen system ......................................2

3. Implementation of zirconium hydriding model into FEM code Bison ..............................3

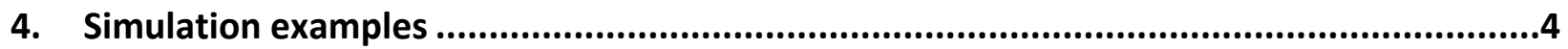

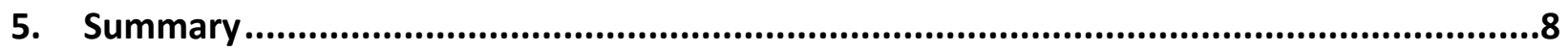

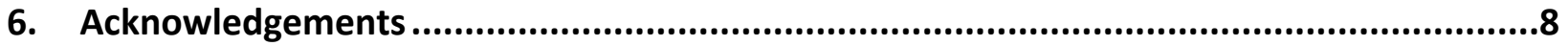

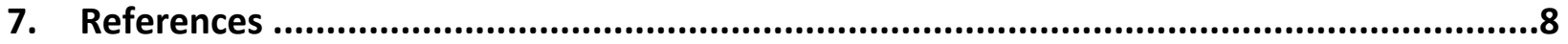




\begin{abstract}
The report describes implementation of the thermodynamics models for simulation of zirconium hydride formation in LWR fuel cladding. The current models for $\mathrm{ZrH}_{\mathrm{x}}$ formation are based on empirical rate models that must calibrated to materials and regimes of interest. The thermodynamic approach enables hydride formation calculations based on fundamental thermodynamics principles and material composition. Thermodynamic formulations and models were implemented in the Idaho National Laboratory fuel performance code Bison using Material, Kernel and AuxKernel methods. The results for the Material and Kernel implementation are shown in this report. The Material method implementation naturally fits the concept of modeling evolution of material state in the material models. Given the relatively high cost of thermodynamic computation, the advantage of the AuxKernel compared to Material implementation is the ability to control the execution and computational cost. The implemented formulations are illustrated on example problems which fit the experimental data and satisfy the computational requirements of conservation equations.
\end{abstract}

\title{
1. INTRODUCTION
}

Hydrogen absorption and formation of hydrides in the cladding tubes of nuclear fuel elements can be detrimental their structural integrity [1]. Depending on the operating conditions, the absorbed hydrogen can exist in a solid solution of zirconium alloy, or it can bond with zirconium into various hydride forms. The associated misfit strains between metal and hydride phases lead to elastic and plastic deformations, internal stresses and stress concentrations $[2,3]$. The understanding and prediction of formation, distribution, and morphology of hydrides are important for extending the burnup of nuclear elements [4].

The hydrogen ingress into fuel element cladding can be related to the fuel burnup and corrosion [1]. Once the solubility of the hydrogen in Zircaloy metal matrix has been exceeded, various forms of hydrides begin to form. The hydride precipitation and dissolution models are based on super- and under- saturation of hydrogen, respectively, from the normal solution state in the metal matrix. The experiments have shown hysteresis in the process of precipitation and dissolution, that are described by two equilibrium parameters, Terminal Solid Solubility for precipitation (TSSp), and Terminal Solid Solubility for dissolution (TSSd) [5, 6]. The departure from the equilibrium conditions is used as the driving force for the kinetics of the process [7-9]. These models for zirconium hydride kinetics [10,11] have been recently implemented in the INL nuclear fuel performance code Bison [12]. The models depend on calibration of various equilibrium and kinetic parameters. It was argued that the composition has little effect on the solubility parameters $[5,7,13]$, although the authors provide notably different values.

In contrast to the kinetic models, the thermodynamic models determine the equilibrium chemical composition of the material. They do not consider the kinetics of the chemical process. For a given elemental composition, pressure and temperature, the equilibrium solver determines a unique combination of phases and their compositions at thermochemical equilibrium. Chemical equilibrium is not achieved instantaneously, but the chemical kinetics may not be very significant for sufficiently high temperatures, long time periods, and when atoms of the various chemical elements are randomly mixed in the system. In nuclear fuels problems under normal operating conditions, chemical equilibrium is achieved quickly due to the high temperatures, and the chemical reactions occur over long time periods. Thermochimica 
[14] is a software library developed for calculation of thermochemical equilibrium at a prescribed composition, temperature and pressure. It has been integrated into nuclear fuel code Bison and used for modeling various aspects of nuclear chemistry. Thermochemica model consists of a library of material thermodynamic properties, thermodynamic models, and a numerical solver to minimize global Gibbs energy while respecting the Gibbs Phase Rule and conservation of mass.

In this report, we describe the implementation of the thermodynamic-based model for the $\mathrm{Zr}-\mathrm{H}$ system for modeling zirconium hydride formation in nuclear fuel element cladding. The $\mathrm{Zr}-\mathrm{H}$ material system is described by a thermodynamic model which is used as an input for the thermodynamic equilibrium solver. In the next section, we provide a brief description of the thermodynamic model for $\mathrm{Zr}-\mathrm{H}$ system. The implementation of various Zircaloy models is available in the literature which can be substituted into the existing framework. The implementation of the model in Bison using Material, Kernel and AuxKernel modules is described after that. Finally, simple benchmark examples are presented illustrating the performance and consistency of the implementation. A journal paper is in preparation. It will compare the models with experiments for which additional Zircaloy thermodynamic material models are under development.

\section{THERMODYNAMIC MODELS FOR ZIRCONIUM - HYDROGEN SYSTEM}

The thermo-chemical solver, Thermochimica, was used for determining equilibrium phases for the $\mathrm{Zr}-\mathrm{H}$ system, their chemical composition and distribution, including metallic $\mathrm{Zr}$ phases with dissolved $\mathrm{H}$. The results from the thermo-chemical solver can also be used for determining other physical properties and models, such as heat capacity, thermal conductivity, etc.

Figure 1 shows the phase diagram of the $\mathrm{Zr}-\mathrm{H}$ system created using the developed thermodynamic model based on reference [15]. The phase diagram illustrates the primary phase regions of interest on the lower hydrogen side of the diagram: hexagonal closed packed (hcp) $\alpha-Z r$, body centered cubic (bcc) $\beta-Z r$, face centered cubic (fcc) $\delta-\mathrm{ZrH}_{2-\mathrm{x}}$, and the two-phase regions $\alpha+\beta$ and $\alpha+\delta$. 


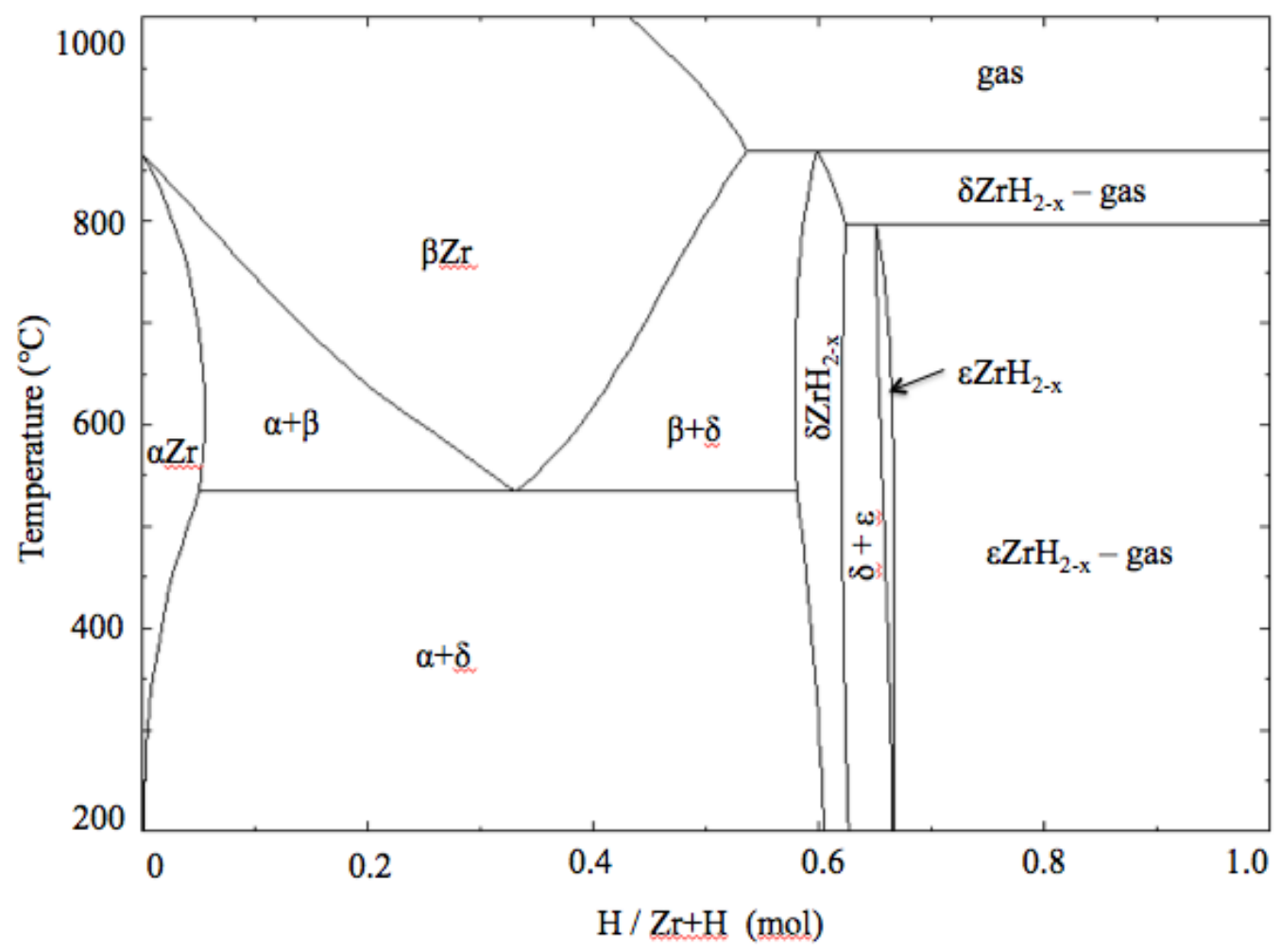

Figure 1. Zirconium-Hydrogen Phase Diagram as Calculated by Thermochimica

Thermochimica calculations were in a close agreement with the commercial thermochemical equilibrium solver FactSage [16]. The $\alpha-\mathrm{Zr}$ solid solution has a maximum hydrogen solubility of 5.5 at. $\%$ at $\sim 615^{\circ} \mathrm{C}$. However, at the nominal outer clad wall temperature of $340^{\circ} \mathrm{C}$ and inner wall temperature of $375^{\circ} \mathrm{C}$, the terminal hydrogen solubility is $\sim 0.83$ at. $\%$ and $\sim 1.1$ at. $\%$, respectively. In this temperature range, the $\delta$ phase will begin to precipitate once the solubility limit has been reached.

\section{IMPLEMENTATION OF ZIRCONIUM HYDRIDING MODEL INTO FEM CODE BISON}

The developed material and transport models use two variables for describing hydrogen in the system. Concentrations are expressed in terms of the amount of hydrogen in a specific phase with respect to the total volume of a computational element (i.e. finite element) that contains all phases. The first variable, named Css, represents wt.ppm concentration of hydrogen in the $\alpha$ phase (metallic Zr containing dissolved $\mathrm{H}$, where $\mathrm{H}$ occupies tetrahedral sites within the hcp cell). The second variable, $\mathrm{Cp}$, represents wt.ppm concentration of hydrogen in the hydride phases, in our case $\delta$ phase $\left(\mathrm{ZrH}_{2-\mathrm{x}}\right)$, that is assumed to be immobile and not participating in hydrogen diffusion. In contrast to models that use separate rate equations for hydrogen transitioning between the two phases, we use the thermodynamics solver to partition the two phases and their respective species. It is assumed that hydrogen in Css is diffusing and thus it is used as the basic variable for the hydrogen diffusion model. The diffusion volume does not change during simulation as it is assumed that the volume fraction of the $\delta$ phase is small. 
The model includes several coupled physics models:

a) heat equation

$$
\rho C_{p} \frac{\partial T}{\partial t}-\nabla \cdot k \nabla T-q=0
$$

b) hydrogen transport

$$
J=-D\left(\nabla H_{S S}+\frac{Q^{*} H_{S S}}{R T^{2}} \nabla T\right) \quad \frac{\partial H_{s S}}{\partial t}-\nabla \cdot J-Q=0
$$

c) zirconium hydride precipitation and dissolution

$$
Q=\frac{H_{Z r H_{x}}^{(t+\Delta t)}-H_{Z r H_{x}}^{(t)}}{\Delta t}
$$

where $H_{s s}$ denotes volume concentration of hydrogen that is contained solid solution, i.e. value derived from Css. $H_{Z r H x}$ denotes concentration of hydrogen stored in hydrides, i.e. valued derived from $\mathrm{Cp}$. The rest of the symbols conform to the standard nomenclature of the respective equations.

The thermodynamic model for the $\mathrm{Zr}-\mathrm{H}$ material system is implemented using Bison Material method. The source/sink is implemented using the Kernel method. The alternative implementation uses the AuxKernel method. The AuxKernel implementation has advantage that user can control the evaluation and, thereby, manage the computational cost, which for thermodynamic solvers is considerable. In this report, only the Material method implementation will be used as the AuxKernel implementation may have to be adjusted due to recent changes in Bison.

The Material model is implemented in updated version of MaterialHZrH.C function. The updated hydrogen source/sink Kernel is HZrHSource. C. The latter is used for both Css and Cp variables, but with different signs since the source of one is the sink of the other, and vice versa. Monomial, constant value finite elements are more practical in cases where large variations of the values occur.

\section{SIMULATION EXAMPLES}

Several example cases were used to validate the model. The tested thermodynamic model for $\mathrm{Zr}-\mathrm{H}$ system has a lower solubility limit compared to values used in literature. Models for Zircaloys are under implementation and compared to the experimental data. The first set of experiments used one fine element with prescribed temperature and hydrogen concentration. The partition of the hydrogen into solid solution and hydrides for different temperatures $(\mathrm{T})$ and initial hydrogen concentrations $(\mathrm{H})$ is shown in Figure 2. 

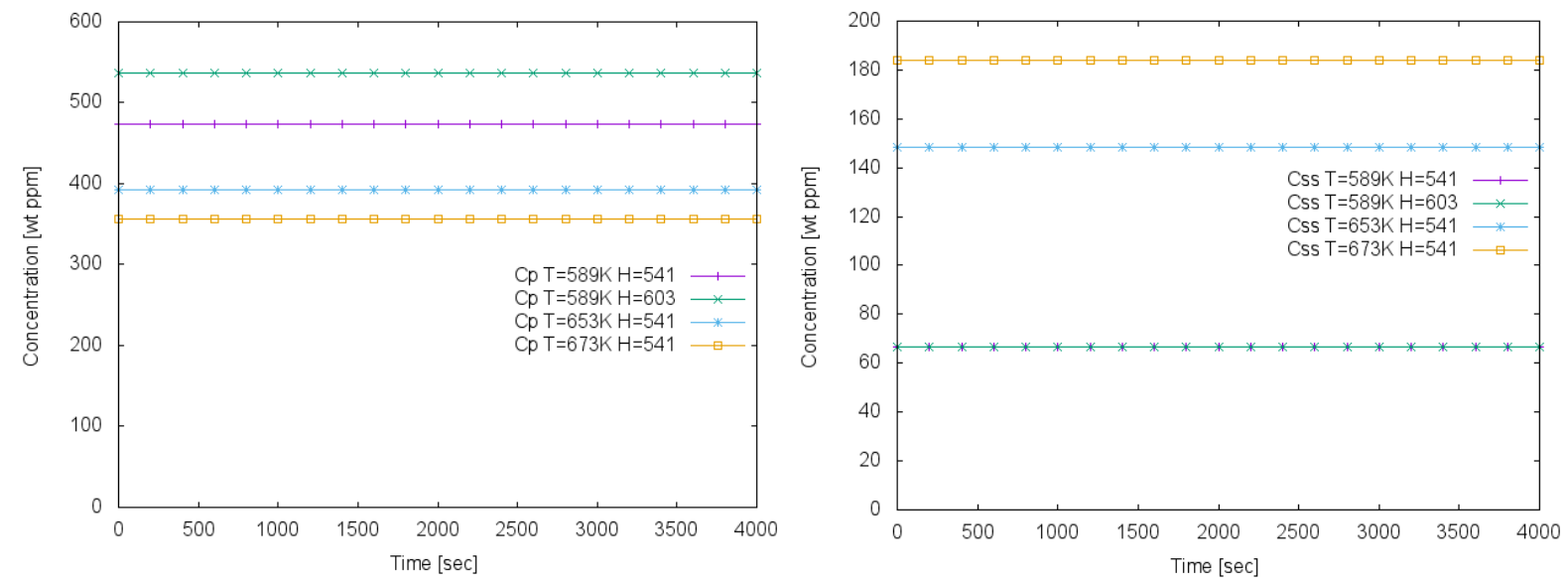

Figure 2: Concentration of hydrogen in hydrides ( $\mathrm{Cp}$ ) and solid solution (Css) for different temperatures (T) and initial hydrogen concentration $(\mathrm{H})$.

The partition of hydrogen agrees with the thermodynamic model and phase diagram. The constant value and conservation over the simulation time illustrate the stability of the model.

The next example uses one variable, hydrogen in solid solution, Css, and monomial finite elements. The initial concentration of $400 \mathrm{wt}$.ppm of hydrogen is used. Temperature gradient of $100 \mathrm{~K}$ is imposed. The evolution of hydrogen concentration in solid solution and hydrides, temperatures, and total hydrogen is shown in Figure 3. The total concentration stays constant which shows the stability of the implemented methods. 


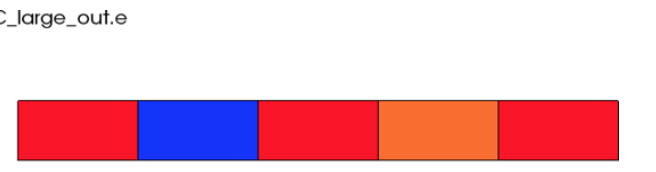

DB: zrhC5PREC_large_out.e

choda
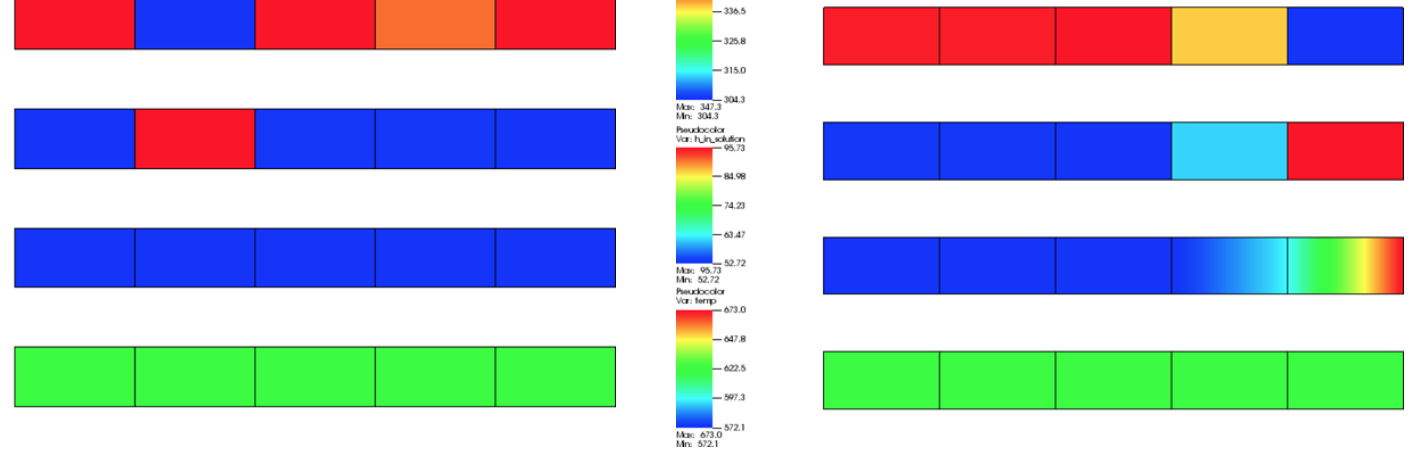

DB: zrhC5PREC_large_out.e

Time:4000

DB: zrhC5PREC_large_out.e
Time: 6000

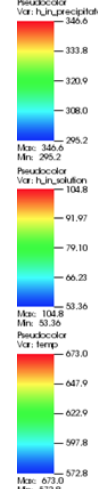
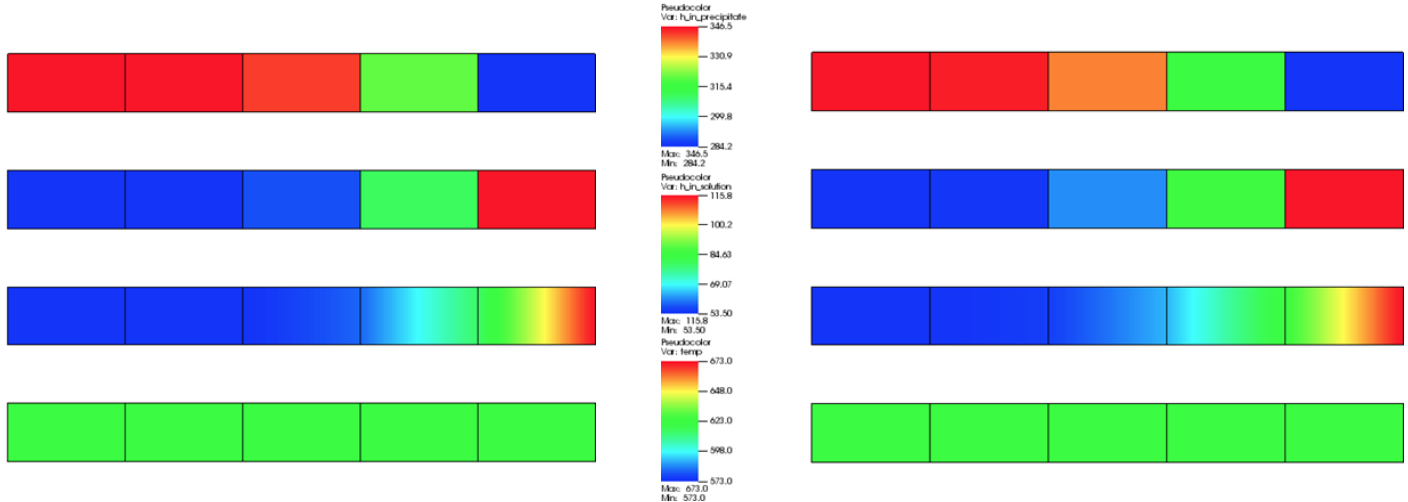

DB: zrhC5PREC_large_out.e

Time: 8000

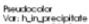

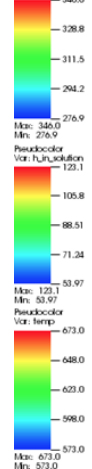
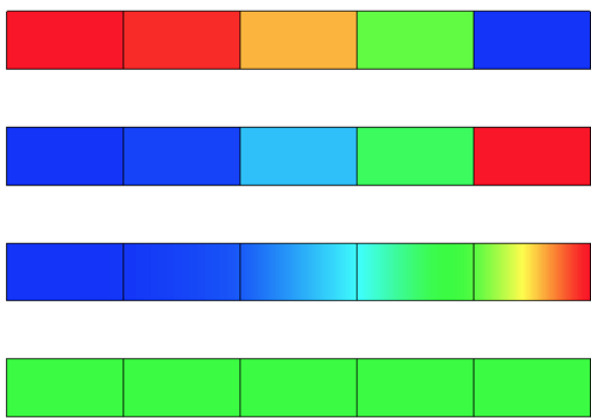

DB: zrhC5PREC_large_out.e
Time: 10000
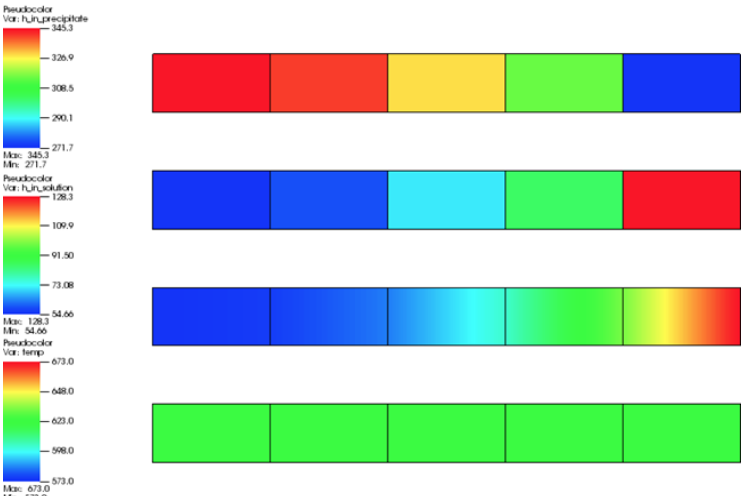

Figure 3: Evolution of hydrogen concentration in hydrides (top bar), hydrogen concentration is solution (second bar from the top), temperature (third bar), and total hydrogen concentration (fourth bar)

In the next example, we use linear finite elements. In this case we use two variables similar to the implementation in References [10,11]. The first variable represents the hydrogen in solid solution, Css, and the second variable, $\mathrm{Cp}$, represents the hydrogen in hydrides. 


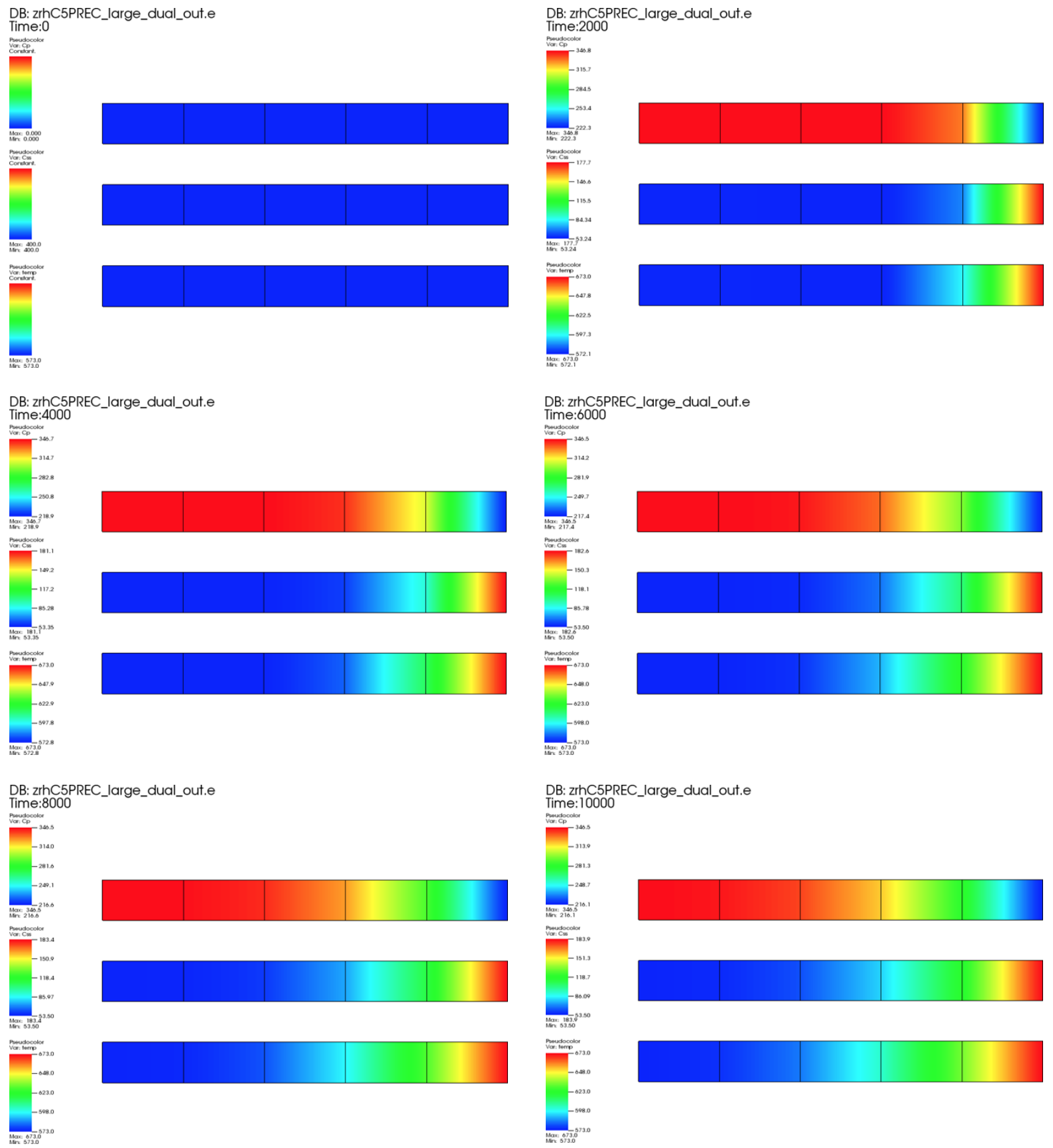

Figure 4: Evolution of hydrogen concentration in hydrides (top bar), hydrogen concentration is solution (second bar from the top), and temperature (third bar)

As for the case of the monomial finite elements, the total concentration of hydrogen is conserved, and the values correspond to the equilibrium values for the thermodynamic model. 


\section{SUMMARY}

We have developed thermodynamics-based model for precipitation, dissolution and transport of hydrogen in zirconium hydrogen system. The model used two variables for describing partition of hydrogen concentration in the system, (a) hydrogen in the $\alpha$ zirconium phase and (b) hydrogen in the $\mathrm{ZrH}_{2-\mathrm{x}} \delta$ phase. Partitioning of hydrogen between the two phases is based on thermochemical equilibrium model for the system. The model is implemented in finite element method code Bison using Material, Kernel, and AuxKernel methods. The implementation is demonstrated on simple examples with constant and varying temperatures.

\section{ACKNOWLEDGEMENTS}

This research was supported by the U.S. Department of Energy, Office of Nuclear Energy, Nuclear Energy Advance Modeling and Simulation Program and Fuel Cycle R\&D Program.

\section{REFERENCES}

[1] H. G. Weidinger, "PWR and WWER Fuel Performance. A Comparison of Major Characteristics," presented at the 6th International Conference On Wwer Fuel Performance, Modelling And Experimental Support, Albena, Bulgaria, 2005.

[2] M. P. Puls, The Effect of Hydrogen and Hydrides on the Integrity of Zirconium Alloy Components. Springer-Verlag, 2012.

[3] A. T. W. Barrow, A. Korinek, and M. R. Daymond, "Evaluating zirconium-zirconium hydride interfacial strains by nano-beam electron diffraction," Journal of Nuclear Materials, vol. 432, no. 1-3, pp. 366-370, Jan 2013.

[4] A. T. Motta and L.-Q. Chen, "Hydride Formation in Zirconium Alloys," Jom, vol. 64, no. 12, pp. 1403-1408, Dec 2012.

[5] A. McMinn, E. C. Darby, and J. S. Schofield, "The terminal solid solubility of hydrogen in zirconium alloys," Zirconium in the Nuclear Industry: Twelfth International Symposium, vol. 1354, pp. 173-195, 2000.

[6] J. J. Kearns, "TERMINAL SOLUBILITY AND PARTITIONING OF HYDROGEN IN ALPHA PHASE OF ZIRCONIUM ZIRCALOY-2 AND ZIRCALOY-4," Journal of Nuclear Materials, vol. 22, no. 3, pp. 292-\&, 1967.

[7] B. Kammenzind, DG Peters, HR Duffin, WJ, "Hydrogen Pickup and Redistribution in AlphaAnnealed Zircaloy-4," presented at the Zirconium in the Nuclear Industry: Eleventh International Symposium, 1996.

[8] O. Courty, A. T. Motta, and J. D. Hales, "Modeling and simulation of hydrogen behavior in Zircaloy-4 fuel cladding," Journal of Nuclear Materials, vol. 452, no. 1-3, pp. 311-320, Sep 2014.

[9] O. F. Courty, A. T. Motta, C. J. Piotrowski, and J. D. Almer, "Hydride precipitation kinetics in Zircaloy-4 studied using synchrotron X-ray diffraction," Journal of Nuclear Materials, vol. 461, pp. 180-185, Jun 2015. 
[10] O. F. Courty, "Hydrogen Distribution in Zircaloy under a Temperature Gradient: Modeling, Simulation and Experiments," MS, Department of Mechanical and Nuclear Engineering, The Pennsylvania State University, 2013.

[11] E. Lacroix, "Hydrogen Distribution in Zircaloy Under a Temperature Gradient: A Benchmark Study," Master of Science Department of Mechanical and Nuclear Engineering The Pennsylvania State University, 2016.

[12] J. D. Hales et al., "Advanced multiphysics coupling for LWR fuel performance analysis," Annals of Nuclear Energy, vol. 84, pp. 98-110, Oct 2015.

[13] K. Une and S. Ishimoto, "Dissolution and precipitation behavior of hydrides in Zircaloy-2 and high Fe Zircaloy," Journal of Nuclear Materials, vol. 322, no. 1, pp. 66-72, Oct 2003.

[14] M. H. A. Piro, S. Simunovic, T. M. Besmann, B. J. Lewis, and W. T. Thompson, "The thermochemistry library Thermochimica," (in English), Computational Materials Science, Article vol. 67, pp. 266-272, Feb 2013.

[15] N. Dupin, I. Ansara, C. Servant, C. Toffolon, C. Lemaignan, and J. C. Brachet, "A thermodynamic database for zirconium alloys," Journal of Nuclear Materials, vol. 275, pp. 287295, 1999.

[16] C. W. Bale et al., "FactSage thermochemical software and databases, 2010-2016," CalphadComputer Coupling of Phase Diagrams and Thermochemistry, vol. 54, pp. 35-53, Sep 2016. 